\title{
Assessment of the thickness of the right ventricular free wall by magnetic resonance imaging in patients with hypertrophic cardiomyopathy
}

\author{
JUN-ICHI SUZUKI, TSUGUYA SAKAMOTO, KATSU TAKENAKA, \\ KIYOSHI KAWAKUBO, KEIKO AMANO, HISAKO TAKAHASHI, \\ ICHIRO HASEGAWA, TAKAHIRO SHIOTA, YOSHIYUKI HADA, \\ TSUNEAKI SUGIMOTO, JUN-ICHI NISHIKAWA *
}

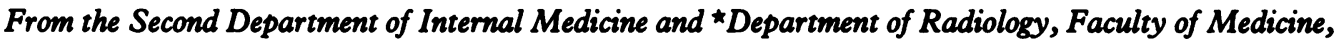
University of Tokyo, Hongo, Bunkyo-Ku, Tokyo, Japan

SUMMARY Electrocardiogram gated magnetic resonance imaging was performed in nine healthy volunteers, in four patients with pulmonary hypertension, and in 16 patients with hypertrophic cardiomyopathy. Fifty two short axis images in diastole were examined to assess the usefulness of magnetic resonance imaging for the measurement of the thickness of the free wall of the right ventricle and the degree of hypertrophy of the right ventricular free wall in hypertrophic cardiomyopathy and pulmonary hypertension. Magnetic resonance imaging gave a clear image of $68 \%$ of the length of the right ventricular free wall, showing both the endocardial and epicardial margins. The mean (1 SD) thickness of the right ventricular free wall measured at a total of 512 points was $0.44(0.12) \mathrm{cm}$ in patients with hypertrophic cardiomyopathy, $0.29(0.08) \mathrm{cm}$ in healthy individuals, and $0.73(0.27) \mathrm{cm}$ in patients with pulmonary hypertension.

Electrocardiogram gated magnetic resonance imaging is a useful method for the non-invasive evaluation of the left ventricle, ${ }^{12}$ left atrium, thoracic aorta, ${ }^{3}$ and pericardium." It has also been used to estimate the thickness of the wall of the left ventricle. ${ }^{56}$ There are several reports of the measurement of the thickness of the free wall of the right ventricle by echocardiography, ${ }^{7-9}$ but only one by magnetic resonance imaging. ${ }^{10}$ We have assessed whether magnetic resonance imaging can be used to measure the right ventricular free wall, particularly in patients with hypertrophic cardiomyopathy.

\section{Patients and methods}

PATIENTS

We studied 16 patients with hypertrophic cardiomyopathy, four patients with pulmonary hypertension (right ventricular systolic pressures

Requests for reprints to Dr Jun-ichi Suzuki, Second Department of Internal Medicine, Faculty of Medicine, University of Tokyo, Hongo 7-3-1, Bunkyo-Ku, Tokyo 113, Japan.

Accepted for publication 19 May 1988
$>70 \mathrm{~mm} \mathrm{Hg}$ ), and nine healthy volunteers. In all the patients the diagnosis was based on $M$ mode and cross sectional echocardiography ${ }^{11-13}$; cardiac catheterisation was performed in those with hypertrophic cardiomyopathy (table 1)

\section{MAGNETIC RESONANCE IMAGING}

We used an electrocardiogram gated saturation recovery spin echo pulse sequence for imaging on a Magnetom (1.5 tesla). Imaging was triggered by the middle point of the $R$ wave upstroke. The echo time was $34 \mathrm{~ms}$, and all the images were obtained $74 \mathrm{~ms}$ after the triggering point. We used this timing for end

Table 1 Acquisition of data in healthy volunteers and patients

\begin{tabular}{|c|c|c|c|c|c|c|}
\hline \multirow[b]{2}{*}{ Group } & \multicolumn{3}{|c|}{ Short axis image } & \multicolumn{3}{|c|}{ Long axis image } \\
\hline & No & Images & Points & No & Images & Points \\
\hline $\begin{array}{l}\text { Healthy } \\
\text { HC } \\
\text { PH }\end{array}$ & $\begin{array}{r}9 \\
16 \\
4\end{array}$ & $\begin{array}{r}16 \\
31 \\
5\end{array}$ & $\begin{array}{r}159 \\
303 \\
50\end{array}$ & $\begin{array}{l}5 \\
8 \\
0\end{array}$ & $\begin{array}{l}5 \\
8 \\
0\end{array}$ & $\begin{array}{r}28 \\
37 \\
0\end{array}$ \\
\hline Total & 29 & 52 & 512 & 13 & 13 & 65 \\
\hline
\end{tabular}

HC, hypertrophic cardiomyopathy; $\mathrm{PH}$, pulmonary hypertension. 


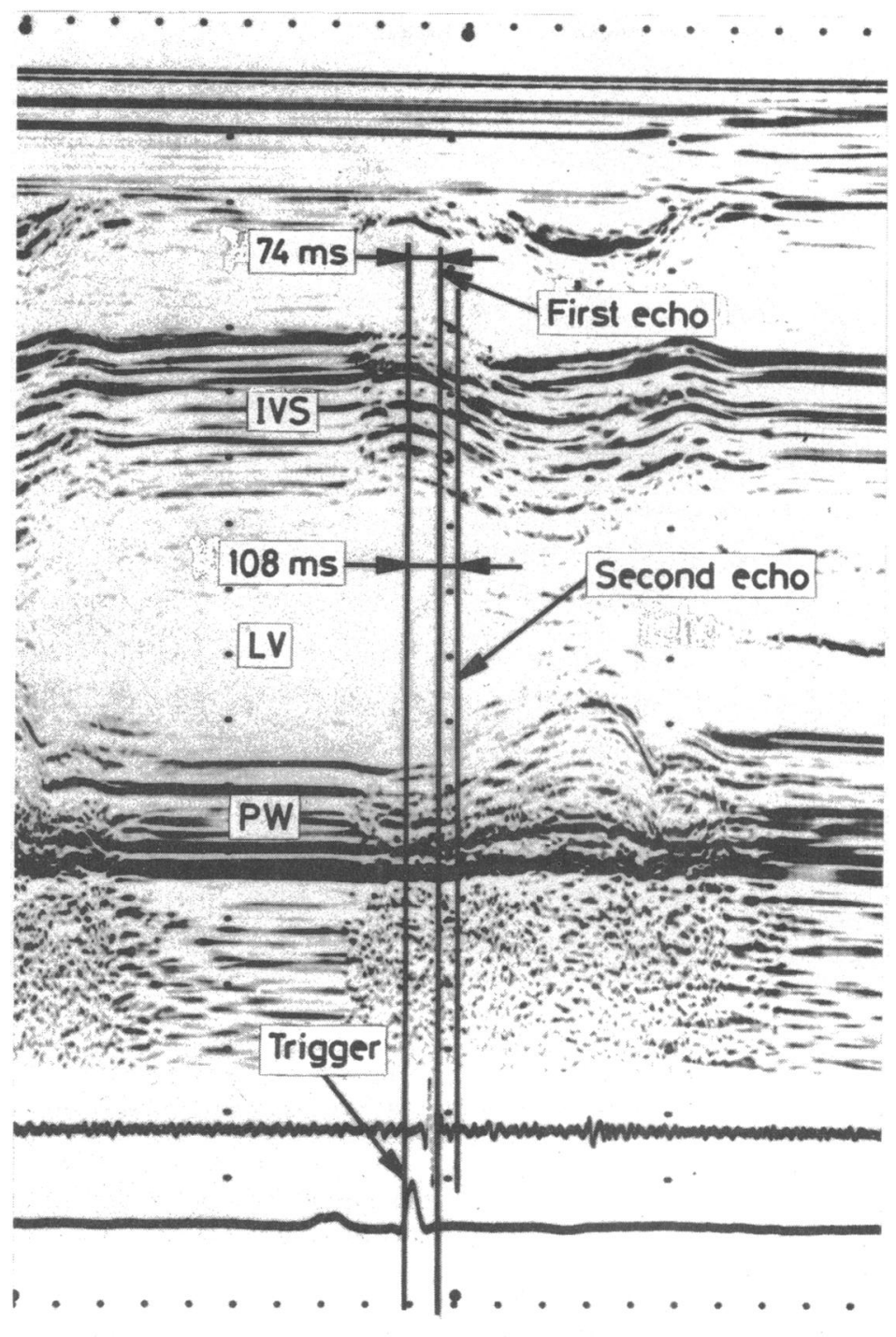

Fig $1 M$ mode echocardiogram showing timing ( $74 \mathrm{~ms}$ after trigger) of the first echo image, which was used for end diastolic measurements. IVS, interventricular septum; $L V$, left ventricle; $P W$, posterior wall of the left ventricle.

diastolic measurements because the timing occurs almost simultaneously with the start of ventricular mechanical contraction (fig 1). The reconstruction matrix was $256 \times 256$ with spatial resolution of $0 \cdot 16$ $0.20 \mathrm{~cm}$. Each cross sectional image was reconstructed for 512-1024 cardiac cycles by a two dimensional Fourier transformation technique. We obtained a long axis image of the left ventricle in the coronal plane in the right anterior oblique position (fig 2b). The degrees were determined individually in the transaxial planes. Then, with the patient in the oblique position, we rotated the gradient angle to obtain the short axis image in the paraxial plane (fig 2d), which was perpendicular to the long axis of the left ventricle; this image was used for the measurements. In 13 of 29 cases we obtained a long axis image (fig $2 \mathrm{c}$ ), that showed the right ventricular free wall. The dual measurements in these individuals permitted us to evaluate the variability in the measurements of the wall thickness in these two 

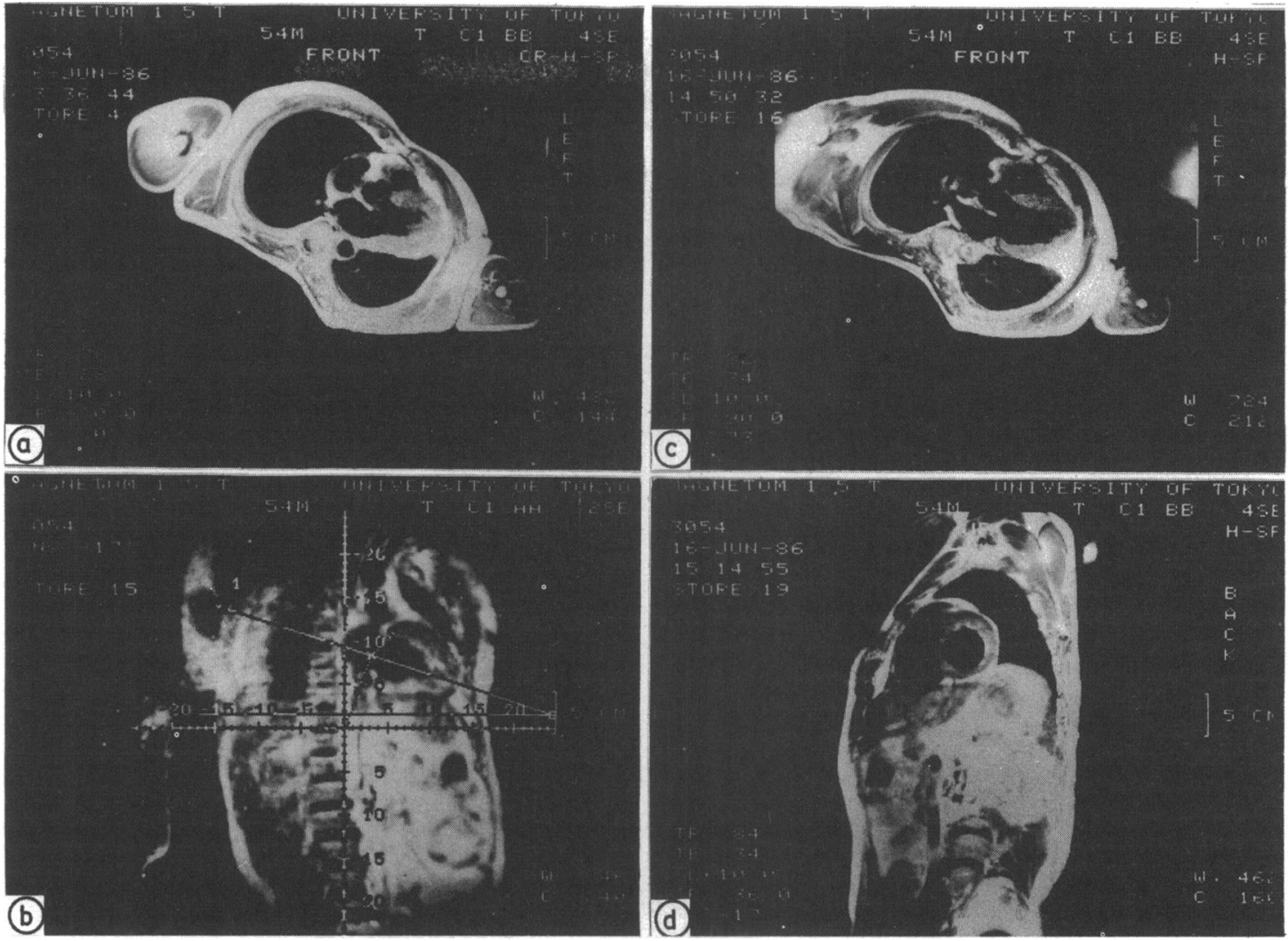

Fig 2 Methods for obtaining short axis image of the heart. (a) Transaxial image obtained in right anterior oblique position so that the coronal plane includes the left ventricular long axis. (b) Long axis image in the coronal plane. (c) Long axis image perpendicular to the image in the coronal plane. This image included the right ventricular free wall and was used to measure the wall thickness and to evaluate variability in measurements from different views. (d) Short axis image in the paraxial plane perpendicular to the coronal plane and to the left ventricular long axis. This image was used for all measurements.

views.

\section{MEASUREMENTS}

We measured the thickness of the right ventricle at centimetre intervals along the wall of the zone with clearly defined endocardial and epicardial margins (fig 3). In each image we measured the length of the free wall and the length of the zone with clearly defined margins. Then we summed the lengths of the free wall and the lengths of the zone with clear margins of all images for each group and calculated the ratio of the zone with clear margins to the length of the free wall. In addition, we measured the maximum and minimum thickness of the free wall and the maximum thickness of the interventricular septum in each image.

\section{CROSS SECTIONAL ECHOCARDIOGRAPHY}

In 19 individuals we measured the thickness of the right ventricular free wall by cross sectional echocar- diography within a few days of the magnetic resonance imaging study. The results of both studies were compared.

\section{VARIABILITY OF MEASUREMENTS FROM DIFFERENT VIEWS}

On the long axis images, the thickness of the free wall of the right ventricle was measured every centimetre in the zone with clearly defined margins. The results were compared with measurements on the short axis images.

\section{STATISTICAL ANALYSIS}

All results were expressed as the mean (1 SD). Differences between two groups were tested by Student's unpaired $t$ test and differences among three groups were analysed by one way analysis of variance. The degree of agreement between the results of measurements made by magnetic resonance imaging with those made by cross sectional 


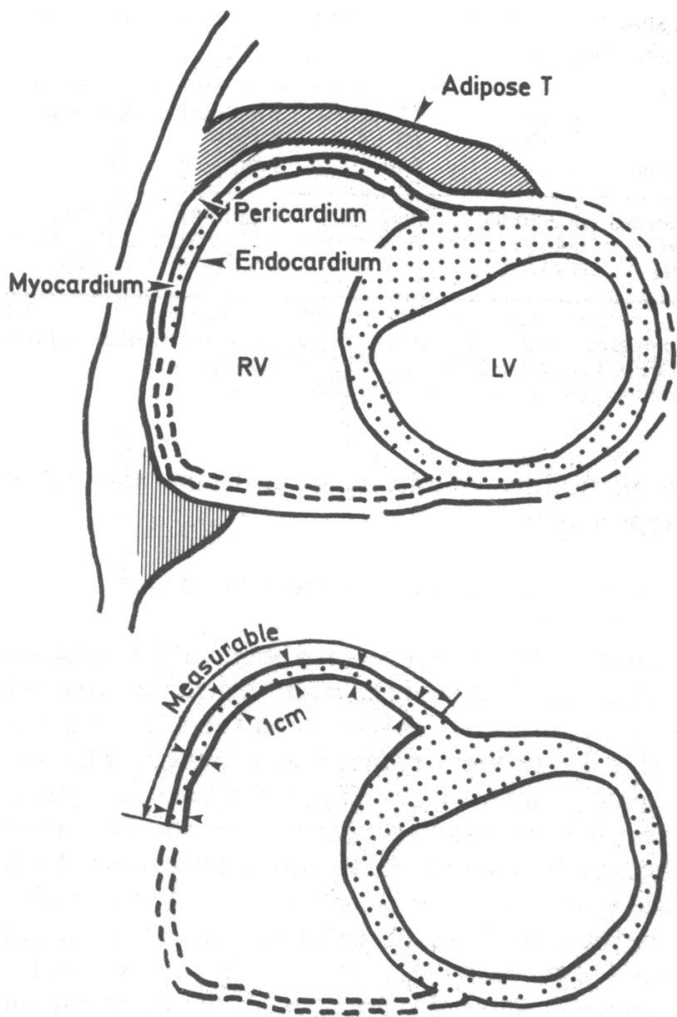

Fig 3 Diagram of the anatomical structures surrounding the right ventricular free wall (upper panel) and the methods of measuring the thickness (lower panel). Wall thickness was measured every $1 \mathrm{~cm}$ where the endocardial and epicardial margins were clearly defined. $L V$, left ventricle; $R V$, right ventricle.

echocardiography was assessed by the method of Bland and Altman. ${ }^{14}$

\section{Results}

In the 16 patients with hypertrophic cardiomyopathy we obtained 31 short axis images and we measured the thickness of the free wall at 303 points (figs 4 and 5 , table 1). The corresponding figures for the nine normal volunteers and four patients with pulmonary hypertension were 16 and five images and 159 and 50 points respectively (figs 6 and 7, table 1).

\section{RATIOS}

The ratios of the length of the zone with clearly defined margins to the length of the right ventricular free wall were $0.65(163.8 \mathrm{~cm} / 251.6 \mathrm{~cm})$ in healthy volunteers, $0.71(311.2 \mathrm{~cm} / 439.6 \mathrm{~cm})$ in patients with hypertrophic cardiomyopathy, $0.63(50.7 \mathrm{~cm} /$

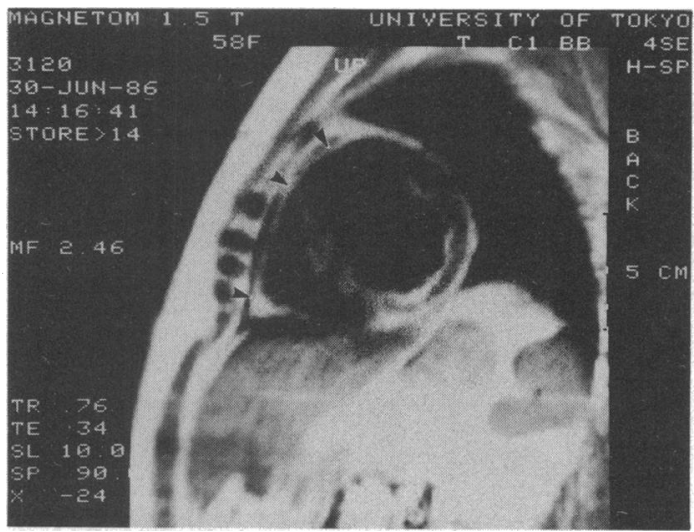

Fig 4 A cross sectional image in a patient with hypertrophic cardiomyopathy with obstruction of the left and right ventricular outflow tracts. Arrows indicate the free wall of the right ventricle. Where the endocardial and epicardial margins of the right ventricle were clearly distinguishable the thickness of the free wall was measured every $1 \mathrm{~cm}$.

$81.1 \mathrm{~cm}$ ) in patients with pulmonary hypertension, and $0.68(525.7 \mathrm{~cm} / 772.3 \mathrm{~cm})$ in the total study group. Magnetic resonance imaging enabled us to measure the thickness of $68 \%$ of the length of the right ventricular free wall.

\section{COMPARISON OF MAGNETIC RESONANCE \\ IMAGING WITH CROSS SECTIONAL BCHOCARDIOGRAPHY}

The mean difference (d) between the measurements obtained by the two methods was $-0.04 \mathrm{~cm}$ and its standard deviation (s) was $0.06 \mathrm{~cm}$. The standard errors of $d$ and of $(d-2 s)$ were $0.01 \mathrm{~cm}$ and $0.02 \mathrm{~cm}$ respectively. The value of the appropriate point of

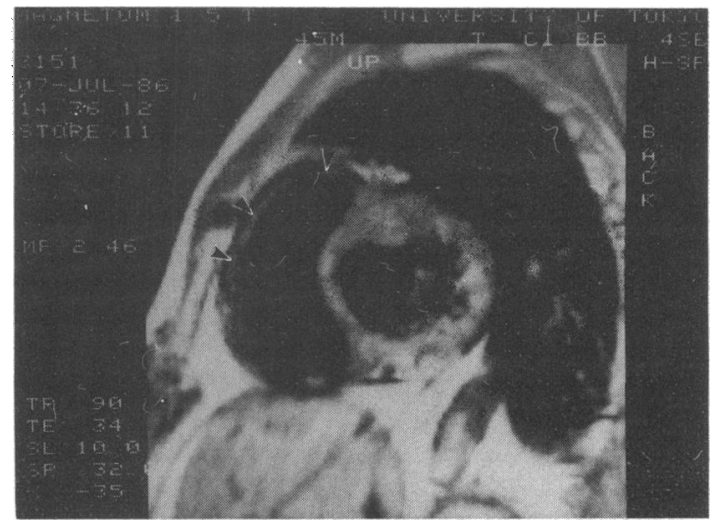

Fig $5 A$ cross sectional image in a patient with hypertrophic cardiomyopathy without left and right ventricular outflow obstructions. Arrows show the free wall of the right ventricle. 


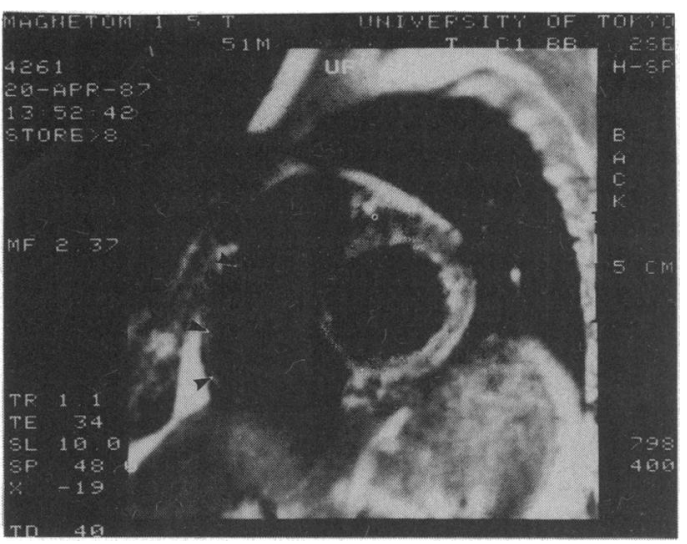

Fig 6 A cross sectional image in a healthy volunteer. Arrows show the free wall of the right ventricle.

the $t$ distribution with $18(19-1)$ degrees of freedom for 0.05 was $2 \cdot 10$. The $95 \%$ confidence interval for the bias was -0.06 to $-0.02 \mathrm{~cm}$. The confidence intervals for the lower limit of agreement and for the upper limit of agreement were -0.02 to $-0.12 \mathrm{~cm}$ and 0.04 to $0.12 \mathrm{~cm}$ respectively.

\section{RIGHT VENTRICULAR FREE WALL THICKNESS}

The mean thickness at 159 points in healthy volunteers, at 303 points in the patients with hypertrophic cardiomyopathy, and at 50 points in the patients with pulmonary hypertension was $0.29(0.08) \mathrm{cm}, 0.44$ $(0.12) \mathrm{cm}$, and $0.73(0.27) \mathrm{cm}$ respectively, and the differences among three groups were statistically significant $(p<0.01)$ (table 2$)$. The thickest free walls in all patients with hypertrophic cardiomyopathy and in all patients with pulmonary hypertension were $0.7 \mathrm{~cm}$ and $1.4 \mathrm{~cm}$ respectively. The thickest and the thinnest free wall thicknesses

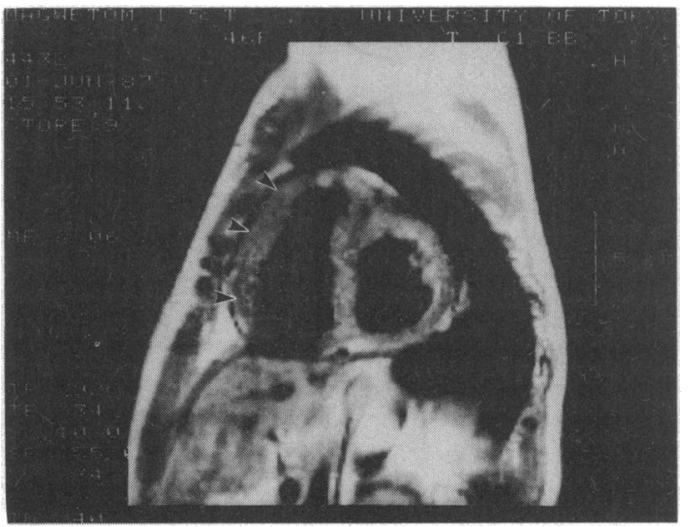

Fig 7 A cross sectional image in a patient with pulmonary hypertension. Arrows show the free wall of the right ventricle.
Table 2 Thickness (mean (1SD)) of the free wall of the right ventricle

\begin{tabular}{|c|c|c|c|c|}
\hline Grousp & $\begin{array}{l}\text { Mean } \\
R V F W T \\
\text { (cm) }\end{array}$ & $\begin{array}{l}\text { Maximuom } \\
R V F W T \\
\text { (cm) }\end{array}$ & $\begin{array}{l}\text { Minimuom } \\
R V F W T \\
(\mathrm{~cm})\end{array}$ & $\begin{array}{l}\text { Maximum } \\
\text { IVS } \\
\text { (cm) }\end{array}$ \\
\hline $\begin{array}{l}\text { Normal } \\
\text { HC } \\
\text { PH }\end{array}$ & $\begin{array}{l}0.29(0.08) \\
0.44(0.12)^{\star \star \star \star ~} \\
0.73(0.27)\end{array}$ & $\begin{array}{l}0.42(0.05) \\
0.59(0.10)^{\star} \\
0.90(0.35)\end{array}$ & $\begin{array}{l}0.21(0.03) \\
0.31(0.07)^{\star} \\
0.52(0.18)\end{array}$ & $\begin{array}{l}1.1(0.1) \\
2.2(0.8)^{\star \star \star \star \star ~} \\
1.0(0.2)\end{array}$ \\
\hline
\end{tabular}

"p $<0.01$ compared with healthy volunteers; ${ }^{\star \star} p<0.01$ compared with PH group. IVS, interventricular septum; RVFWT, thickness of the right ventricular free wall. See footnote to table 1 for other abbreviations.

in all healthy volunteers were $0.5 \mathrm{~cm}$ and $0.2 \mathrm{~cm}$ respectively.

\section{VARIABILITY IN MEASUREMENTS FROM DIFFERENT VIEWS}

In five healthy volunteers we obtained five long axis images that included the right ventricular free wall and we measured the wall thickness at 28 points (table 1). In eight patients with hypertrophic cardiomyopathy we obtained eight long axis images and measured the wall thickness at 37 points. The ratio of the total length of the wall with clear margins to the free wall was $0.62(65.6 \mathrm{~cm} / 105.2 \mathrm{~cm})$ in this view. The mean thickness of the wall measured on the long axis images was $0.29(0.08) \mathrm{cm}$ in the five healthy volunteers and $0.46(0.12) \mathrm{cm}$ in the eight patients with hypertrophic cardiomyopathy. There were no significant differences between thickness measured on the short axis images and that measured on the long axis images.

\section{INTERVENTRICULAR SEPTUM}

The maximal thickness of the interventricular septum was $1.1(0.1) \mathrm{cm}$ in healthy volunteers, 2.2 $(0.8) \mathrm{cm}$ in patients with hypertrophic cardiomyopathy, and $1.0(0.2) \mathrm{cm}$ in patients with pulmonary hypertension.

\section{Discussion}

Cross sectional magnetic resonance images clearly distinguished the right ventricular free wall from other surrounding structures in the present study. Adjacent adipose tissue produced the highest signal intensity outside the pericardium, and the pericardium and intrapericardial cavity gave the lowest intensity line. ${ }^{15}$ The right intraventricular cavity gave the lowest signal intensity. We had no difficulty in distinguishing these structures from the free wall, which produced a signal band of medium intensity. On average we were able to measure the thickness of $68 \%$ of the length of the free wall. We suspect that artefacts caused by chemical shifts or changes in 
heart rate and arrhythmia during scanning prevented the remainder of the free wall being adequately imaged. Histological examination showed that the normal thickness of the right ventricular free wall was $0.2 \mathrm{~cm}$; a wall thickness of $>0.5 \mathrm{~cm}$ was regarded as hypertrophic. ${ }^{716}$

In echocardiographic studies the free wall was reported to be $0.3 \mathrm{~cm}$ thick in healthy volunteers and $0.5 \mathrm{~cm}$ thick in patients with hypertrophic cardiomyopathy'; however, only a limited number of points were measured. The thickness of the free wall of the right ventricle, which was measured by magnetic resonance imaging at 18 points on average in each patient, was compatible with the results of earlier pathological and echocardiographic studies. Foale et al reported that in normal individuals regional variation was quite large for some views. ${ }^{8}$ In the present study, the wall thickness in normal volunteers ranged from $0.2 \mathrm{~cm}$ to $0.5 \mathrm{~cm}$, and there was little variation between measurements on the short axis and long axis images.

Although we used echocardiographic measurements as a reference standard, it was difficult to obtain images of entire free wall by this method. So echocardiographic measurement was performed at one point in every individual. Magnetic resonance imaging has the advantage of imaging more of the right ventricular free wall ( $68 \%$ in this study) than other methods and this ability is likely to be clinically useful in the diagnosis of several heart diseases. We found that the wall thickness in patients with hypertrophic cardiomyopathy seldom exceeded $0.8 \mathrm{~cm}$ but was significantly greater than that of healthy volunteers.

\section{References}

1 Lanzer P, Botvinick EH, Schiller NB, et al. Cardiac imaging using gated magnetic resonance. Radiology 1984;150:121-7.

2 Akins EW, Hill JA, Fitzsimmons JR, Pepine CJ, Williams CM. Importance of imaging plane for magnetic resonance imaging of the normal left ventricle. Am J Cardiol 1985;56:366-72.
3 Schaefer S, Peshock RM, Malloy CR, Katz J, Parkey RW, Willerson JT. Nuclear magnetic resonance imaging in Marfan's syndrome. J Am Coll Cardiol 1987;9:70-4.

4 Soulen RL, Stark DD, Higgins CB. Magnetic resonance imaging of constrictive pericardial disease. $\mathrm{Am} J$ Cardiol 1985;55:480-4.

5 Higgins CB, Byrd BF, Stark D, et al. Magnetic resonance imaging in hypertrophic cardiomyopathy. $A m \mathrm{~J}$ Cardiol 1985;55:1121-6.

6 Been M, Kean D, Smith MA, Douglas RHB, Best JJK, Muir AL. Nuclear magnetic resonance in hypertrophic cardiomyopathy. Br Heart J 1985;54:48-52.

7 Prakash R. Determination of right ventricular wall thickness in systole and diastole: echocardiographic and necropsy correlation in 32 patients. Br Heart $J$ 1978;40:1257-61.

8 Foale R, Nihoyannopoulos P, McKenna W, et al. Echocardiographic measurement of the normal adult right ventricle. Br Heart $J$ 1986;56:33-44.

9 Seo T, Yokota Y, Kumaki T, et al. Regional right ventricular hypertrophy in hypertrophic cardiomyopathy and hypertension. J Cardiogr 1985; 15:339-46 [in Japanese].

10 Markiewicz W, Sechtem U, Higgins CB. Evaluation of the right ventricle by magnetic resonance imaging. Am Heart J 1987;113:8-15.

11 Abbasi AS, MacAlpin RN, Eber LM, Pearce ML. Echocardiographic diagnosis of idiopathic hypertrophic cardiomyopathy without outflow obstruction. Circulation 1972;46:897-904.

12 Rossen RM, Goodman DJ, Ingham RE, Popp RL. Echocardiographic criteria in the diagnosis of idiopathic hypertrophic subaortic stenosis. Circulation 1974;50:747-51.

13 Maron BJ, Henry WL, Roberts WC, Epstein SE. Comparison of echocardiographic and necropsy measurements of ventricular wall thickness in patients with and without disproportionate septal thickening. Circulation 1977;55:341-6.

14 Bland JM, Altman DG. Statistical methods for assessing agreement between two methods of clinical measurement. Lancet 1986;1:307-10.

15 Sechtem U, Tscholakoff D, Higgins CB. MRI of the normal pericardium. $A J R$ 1986;147:239-44.

16 Allenstein BJ, Mori H. Evaluation of electrocardiographic diagnosis of ventricular hypertrophy based on autopsy comparison. Circulation 1960;21:401-12. 